\title{
Exogenous Calcium Improved Resistance to Botryosphaeria dothidea by Increasing Autophagy Activity and Salicylic Acid Level in Pear
}

\author{
Xun Sun, ${ }^{\dagger}$ Bisheng Pan, Yun Wang, Wenyu Xu, and Shaoling Zhang ${ }^{\dagger}$ \\ Center of Pear Engineering Technology Research, State Key Laboratory of Crop Genetics and Germplasm Enhancement, \\ College of Horticulture, Nanjing Agricultural University, Nanjing 210095, China \\ Accepted 19 May 2020.
}

\begin{abstract}
Pear ring rot, caused by Botryosphaeria dothidea, is one of the most serious diseases in pear. Calcium $\left(\mathrm{Ca}^{2+}\right)$ was reported to play a key role in the plant defense response. Here, we found that exogenous calcium could enhance resistance to $B$. dothidea in pear leaves. Less $\mathrm{H}_{2} \mathrm{O}_{2}$ and $\mathrm{O}_{2}^{-}$but more activated reactive oxygen species scavenge enzymes accumulated in calciumtreated leaves than in $\mathrm{H}_{2} \mathrm{O}$-treated leaves. Moreover, the increased level of more ascorbic acid-glutathione was maintained by $\mathrm{Ca}^{2+}$ treatment under pathogen infection. The expression of core autophagy-related genes and autophagosome formations were enhanced in $\mathrm{Ca}^{2+}$-treated leaves. Silencing of PbrATG5 in Pyrus betulaefolia conferred sensitivity to inoculation, which was only slightly recovered by $\mathrm{Ca}^{2+}$ treatment. Moreover, the salicylic acid (SA) level and SA-related gene expression were induced more strongly by $\mathrm{B}$. dothidea in $\mathrm{Ca}^{2+}$-treated leaves than in $\mathrm{H}_{2} \mathrm{O}$-treated leaves. Taken together, these results demonstrated that exogenous $\mathrm{Ca}^{2+}$ enhanced resistance to $B$. dothidea by increasing autophagic activity and SA accumulation. Our findings reveal a new mechanism of $\mathrm{Ca}^{2+}$ in increasing the tolerance of pear to $B$. dothidea infection.
\end{abstract}

Keywords: autophagy, Botryosphaeria dothidea, calcium, pear, salicylic acid

Calcium plays a key role in pear resistance to Botryosphaeria dothidea by increasing autophagy activity and salicylic acid level. Like all living things, the environmental challenges faced by plants can be biological, such as interactions with pathogens, or nonbiological, such as drought, extreme temperatures, and

Xun Sun and Bisheng Pan contributed equally to this work.

${ }^{\dagger}$ Corresponding authors: X. Sun; sunxun1991@ njau.edu.cn and S. Zhang; slzhang@njau.edu.cn

Funding: This work was supported by the Fundamental Research Funds for the Central Universities (KJQN202027), the National Natural Science Foundation of China (31901989), the Natural Science Foundation of Jiangsu Province (BK20190534), the China Postdoctoral Science Foundation (2019M661865), and the Science and Technology Support Program of Jiangsu Province (BE2018389).

*The $\boldsymbol{e}$-Xtra logo stands for "electronic extra" and indicates a supplementary figure and a supplementary table are published online.

The author(s) declare no conflict of interest.

(c) 2020 The American Phytopathological Society mechanical damage. To adapt to adverse growth conditions, plants have evolved a series of strategies to activate appropriate physiological responses. As a second messenger, calcium $\left(\mathrm{Ca}^{2+}\right)$ is widely examined for its protective role in the response to most abiotic stresses, including drought, cold, heat, heavy metals, and oxidative stresses, and particularly in the immune response to pathogens(Aldon et al. 2018; Dai et al. 2012; Khan et al. 2010; Liu et al. 2014). The intracellular calcium concentration can be stimulated by pathogen infection. To be involved in plant defense system, the stimulated $\mathrm{Ca}^{2+}$ messages need to be decoded and relayed to activate the appropriate cellular response, which is carried out by a $\mathrm{Ca}^{2+}$ binding protein called a $\mathrm{Ca}^{2+}$ sensor (Steinhorst and Kudla 2014). Moreover, $\mathrm{Ca}^{2+}$ sensors are mandatory; for example, Arabidopsis is estimated to have more than $250 \mathrm{Ca}^{2+}$ sensor members (Day et al. 2002). The plant $\mathrm{Ca}^{2+}$ sensors were classified into four major groups: the calcineurin B-like group (Luan 2009), the $\mathrm{Ca}^{2+}$ dependent protein kinase group (Cheng et al. 2002), the calmodulin group (Yang and Poovaiah 2003), and its closely related group, the calmodulin-like protein (CML) family (Bender and Snedden 2013). To date, the role of most $\mathrm{Ca}^{2+}$ sensors is largely unknown, but recent studies have indicated some roles of $\mathrm{Ca}^{2+}$ sensors in plant development, abiotic stress responses, and immunity (Rao et al. 2014; Yuan et al. 2017; Zeng et al. 2015). For instance, Arabidopsis CALMODULIN-BINDING PROTEIN60 (CBP60) is involved in the calmodulin-dependent activation of salicylic acid (SA) signaling in response to pathogen recognition (Wang et al. 2009). Moreover, CML46 and CML47 are associated with CBP60a and were reported to negatively control SA accumulation and contribute to resistance to the pathogen Pseudomonas syringae (Lu et al. 2018). Bundó and Coca (2016) found that the overexpression of OsCPK4 improved resistance to blast disease in rice. Liu et al. (2017) reported that CPK5 links with TIR-NBS2 were needed for Arabidopsis immunity. Although recent studies have investigated the in vivo role of calcium when plants are exposed to abiotic stress or in transgenic overexpression plants, the traditional and classical methods is utilizing exogenous calcium. Application of exogenous calcium improved the inhibition of growth and development and maintained the integrity of cell function and structure under abiotic stress. For example, $\mathrm{CaCl}_{2}$ treatment restricted the development of brown spots on pear by improving the structural integrity of the cell membrane (Kou et al. 2015). Exogenous calcium treatment increases biomass and delays the senescence of broccoli microgreens (Kou et al. 2014). In mammal, an increase in calcium induced autophagy under several physiologic and pathologic conditions (Filippi-Chiela et al. 2016; Høyer-Hansen et al. 2007; Kondratskyi et al. 2018). 
However, the molecular mechanism through which calcium promotes resistance to pathogen infection in plants is largely unknown.

Autophagy, a conserved cellular process in eukaryotes, is a universal vesicular mechanism that facilitates the degradation

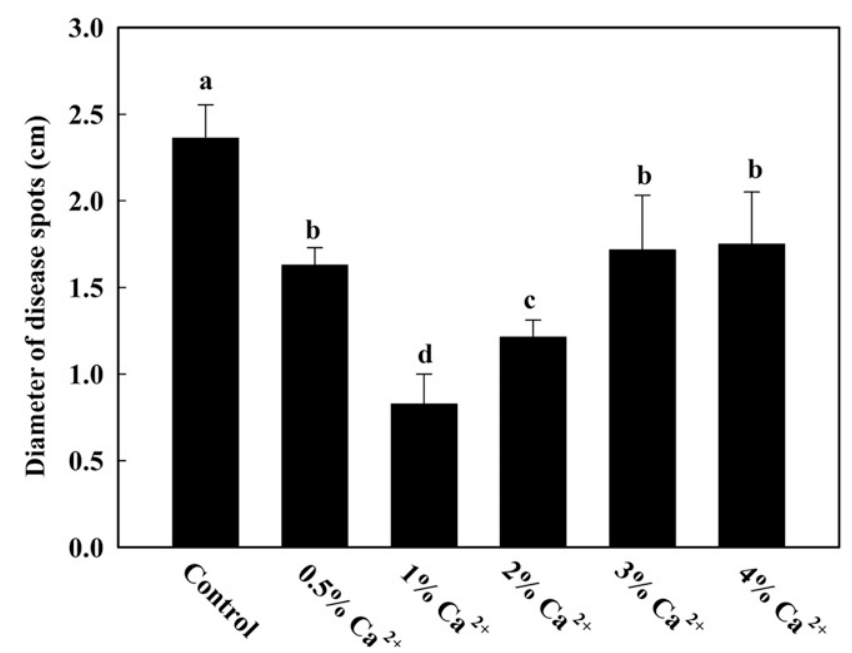

Fig. 1. The diameter of disease spots of leaves treated with different concentrations of $\mathrm{Ca}^{2+}$. Diameter of disease spots was detected at 10 days after inoculation. Data are means of three replicates with standard error. Values not followed by the same letter indicate significant differences between treatments, according to one-way analysis of variance Tukey's multiple range tests $(P<0.05)$. of unwanted cell constituents in eukaryotic cells and plays an important role in recycling nutrients and cytoplasmic components as well as in conferring tolerance to biotic and abiotic stresses (Farré and Subramani 2016; Han et al. 2015; He and Klionsky 2009; Yang and Bassham 2015). To date, more than 35 autophagy-related (ATG) genes have been identified in yeast, and most of them have close homologs in plants (Liu and Bassham 2012; Shibutani and Yoshimori 2014). With the characterization of plant $A T G$ genes, the role of autophagy has been widely revealed, including plant abiotic and biotic stresses, such as seed germination, development, senescence, drought, salt, and plant-pathogen interactions (Chung et al. 2009; Hofius et al. 2017; Qi et al. 2017; Yang et al. 2019). There is convincing evidence that autophagy is required for plant resistance to necrotrophic pathogens. The Arabidopsis mutant atg18a was more hyposensitive to the necrotrophic fungal pathogen Botrytis cinerea (Lai et al. 2011). The Arabidopsis autophagy-deficient mutants atg5, atg10, and atg18a have spreading necrosis areas when infected by Alternaria brassicicola and Plectosphaerella cucumerina (Lenz et al. 2011), while Arabidopsis bag6 (Bcl-2-associated athanogene $6)$ mutants are defective in autophagosome formation and hypersusceptible to $B$. cinerea (Li et al. 2016). These results indicated that autophagy plays a crucial role in plant resistance to necrotrophic pathogen infection.

It is well-known that the plant hormone SA acts in defense signaling in plants (Ding et al. 2018; Fu et al. 2012; Zhao et al. 2019). SA signaling is transduced by the SA receptor, nonexpresser of genes PRI (NPR1). NPR1 interacts with TGA transcription factors in the nucleus and stimulates their DNA
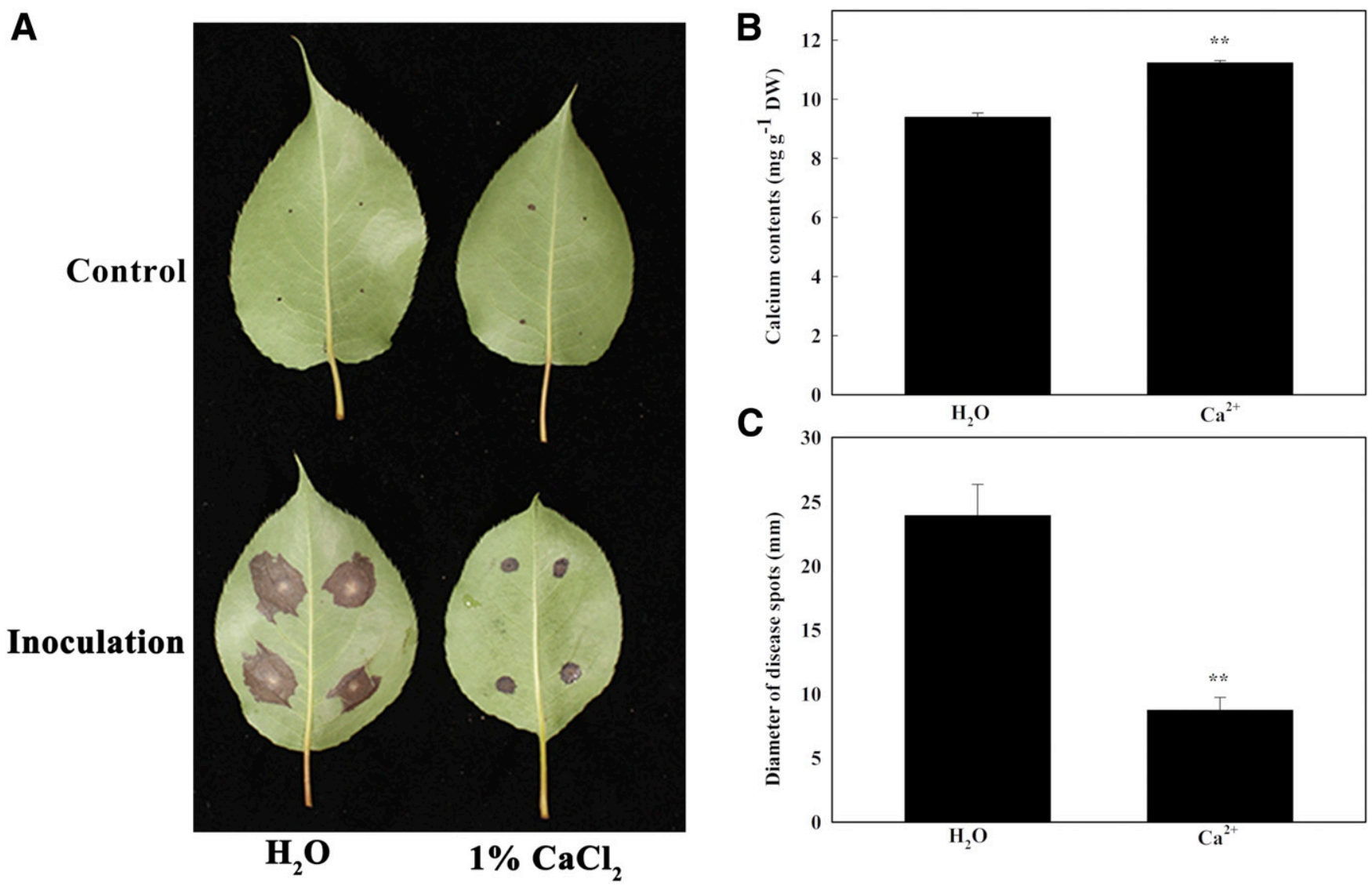

Fig. 2. $\mathrm{Ca}^{2+}$ enhanced the resistance of pear leaves to Botryosphaeria dothidea infection. A, Phenotypes of $\mathrm{H}_{2} \mathrm{O}-$ and $\mathrm{Ca}^{2+}$-treated leaves under mock control and inoculation conditions at 10 days after inoculation (dpi). B. The calcium concentrations in $\mathrm{H}_{2} \mathrm{O}$ - and $\mathrm{Ca}^{2+}$-treated leaves under mock control conditions at 6 dpi. C, The diameter of disease spots of leaves treated with $\mathrm{Ca}^{2+}$ at $10 \mathrm{dpi}$. Data are means of three replicates with standard error. Asterisks denote statistically significant differences between $\mathrm{Ca}^{2+}$ - and $\mathrm{H}_{2} \mathrm{O}$-treated leaves (asterisks [**] mean $P<0.01$, analysis of variance). 
binding activity (Dong 2004). TGA transcription factors bind to cognate elements in promoters of certain genes and enhance their expression including PRI (PATHOGENESIS-RELATED 1 ) and $P R 5$. Recently, it has been reported that SA is involved in plant resistance to Botryosphaeria dothidea. SA improved the tolerance of apple to $B$. dothidea by increasing MdPR4 expression (Bai et al. 2013). Silencing MdSYP121 resulted in enhanced resistance to $B$. dothidea by increasing SA levels (He et al. 2018). Zhao et al. (2019) found that MdWRKY15 improves tolerance to $B$. dothidea by increasing SA synthesis by binding the MdICS1 promoter in apple. Interestingly, studies have reported that $\mathrm{Ca}^{2+}$ signaling is connected to the SAmediated immune response in Arabidopsis (Coca and San Segundo 2010; Du et al. 2009; Wang et al. 2009).
B. dothidea, a necrotrophic pathogen, causes pear ring rot in leaf, branch, and fruit, which is one of the most serious diseases in pear (Pyrus bretschneideri Rehd.) (Kim et al. 2001). However, the resistance mechanism of pear to $B$. dothidea is not clear. In this study, we used exogenous calcium treatment to simulate the increase of calcium concentration in pear leaves. The calcium-treated leaves showed enhanced resistance to $B$. dothidea infection, probably resulting from the decreased $\mathrm{H}_{2} \mathrm{O}_{2}$ and $\mathrm{O}_{2}^{-}$levels. The $\mathrm{Ca}^{2+}$ treatment stimulated stronger enzymatic and nonenzymatic antioxidant under pathogen infection condition. Moreover, the activity of autophagosomes was higher, and SA was accumulated in the $\mathrm{Ca}^{2+}$-treated pear leaves under inoculation. The expression levels of core $A T G$ and SA-related genes were induced to higher levels in
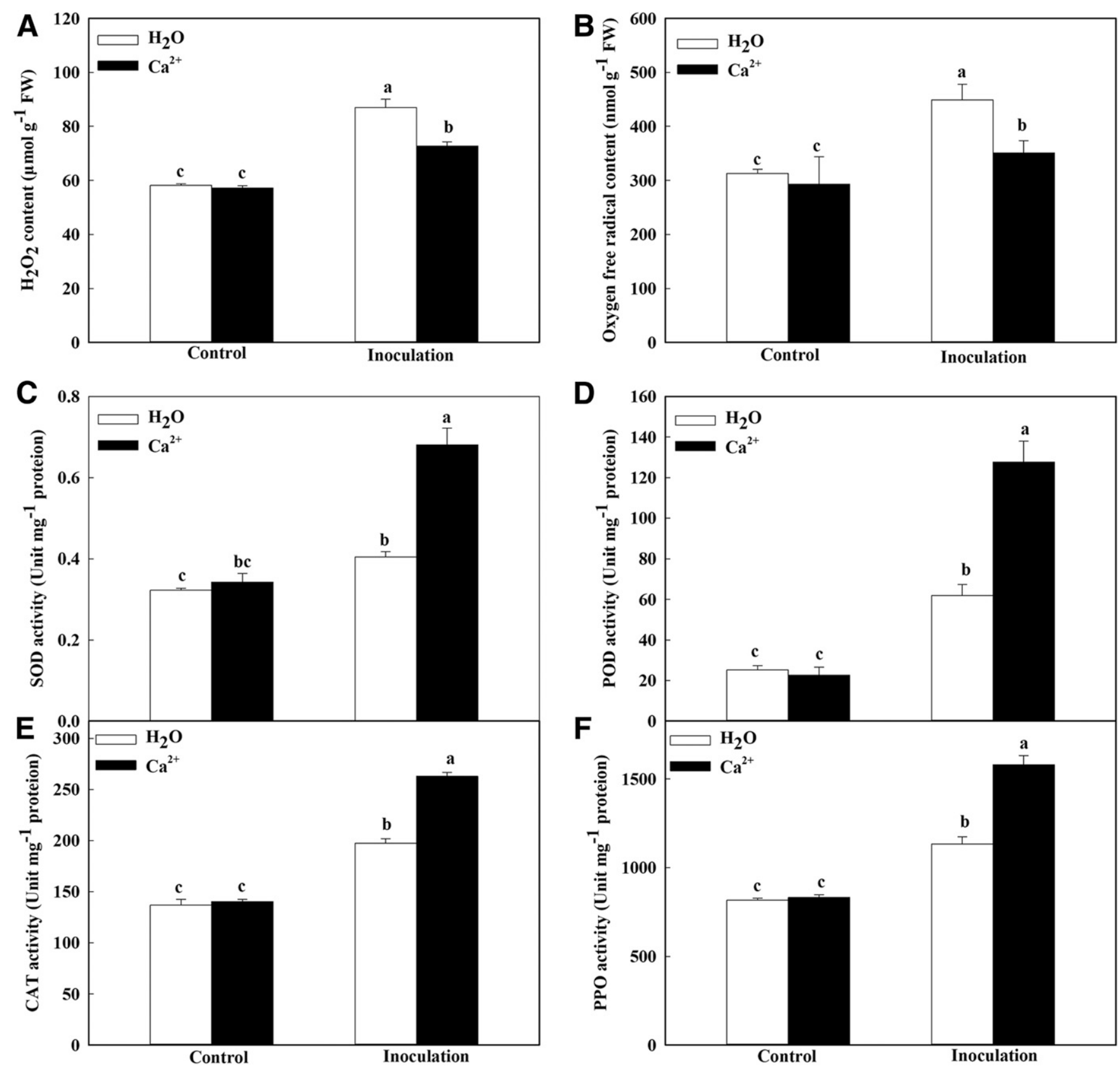

Fig. 3. Changes in levels of reactive oxygen species (ROS) accumulation and activity of ROS-scavenging enzymes in pear leaves under Botryosphaeria dothidea infection. A, Quantitative measurement of $\mathrm{H}_{2} \mathrm{O}_{2}$ and $\mathbf{B}, \mathrm{O}_{2}^{-}$concentrations of pear leaves with and without $\mathrm{Ca}^{2+}$ treatment. $\mathbf{C}$, Activity of superoxide dismutase (SOD), D, peroxidase (POD), E, catalase (CAT) and $\mathbf{F}$, polyphenol oxidase (PPO) at 10 days after inoculation. Data are means of three replicates with standard error. Values not followed by the same letter indicate significant differences between treatments, according to one-way analysis of variance Tukey's multiple range tests $(P<0.05)$. 
$\mathrm{Ca}^{2+}$-treated leaves under $B$. dothidea infection. These results demonstrated that calcium plays a key role in the resistance of pear to $B$. dothidea by enhancing autophagic activity and SA levels.

\section{RESULTS}

\section{Effect of different calcium concentrations} on pear resistance to $B$. dothidea.

Previous studies revealed that exogenous calcium promotes the senescence of broccoli microgreens and browning of pear fruit (Kou et al. 2014, 2015). Here, we applied different concentrations of $\mathrm{CaCl}_{2}$ treatment on Dangshan Su pear (Pyrus bretschneideri Rehd.) leaves. As shown in Figure 1, treatment with 0.5 to $4 \% \mathrm{CaCl}_{2}$ significantly improved resistance to B. dothidea. As the $\mathrm{Ca}^{2+}$ concentration increased (0.5 to $4 \%$ ), the diameter of disease spot increased (Fig. 1). At these concentrations, the effect of $1 \% \mathrm{Ca}^{2+}$ treatment was the most significant. The diameter of the disease spot of $1 \% \mathrm{Ca}^{2+}$-treated leaves was $34.98 \%$ that of $\mathrm{H}_{2} \mathrm{O}$-treated leaves. However, the diameter of the disease spot of $4 \% \mathrm{Ca}^{2+}$-treated leaves was slightly higher but not significantly higher than that of $3 \%$ $\mathrm{Ca}^{2+}$-treated leaves.

\section{Phenotype of $1 \% \mathrm{Ca}^{2+}$-treated leaves and endogenous $\mathrm{Ca}^{2+}$ content.}

As shown in Figure 1, the effect of $1 \% \mathrm{Ca}^{2+}$ treatment was the most significant among different $\mathrm{Ca}^{2+}$ concentrations. Therefore, we chose $1 \% \mathrm{Ca}^{2+}$ to further investigation. The results were consistent with Figure 1 , where $1 \% \mathrm{Ca}^{2+}$ treatment significantly enhanced the resistance of pear to $B$. dothidea. The diameter of disease spots of calcium treated leaves was significantly lower than that of $\mathrm{H}_{2} \mathrm{O}$ treated leaves (Fig. 2C). To examine whether exogenous $\mathrm{Ca}^{2+}$ increased the total calcium content, we also detected the total calcium content in pear leaves. As shown in Figure 2, at 6 days after inoculation (dpi), the calcium content in the treated leaves was significantly higher than that in the control leaves. The calcium content of treated leaves was $19.6 \%$ higher than that of control leaves.
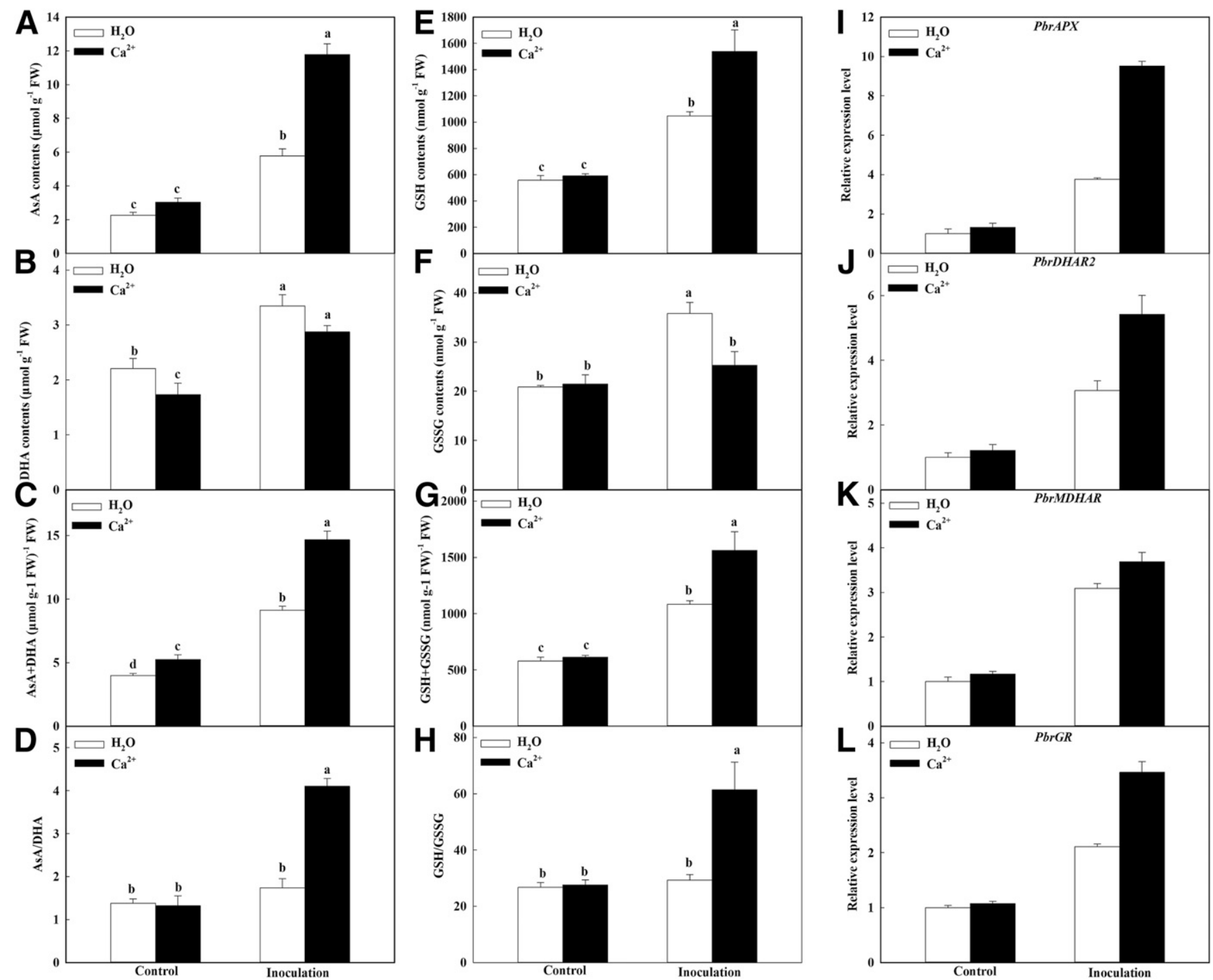

Fig. 4. Changes in antioxidant concentrations of pear leaves and in transcript levels of genes implicated in the AsA-GSH cycle under inoculation. Concentrations of A, ascorbic acid (AsA), B, dehydroascorbate (DHA), C, AsA+DHA, and D, AsA/DHA. E, Concentrations of glutathione (GSH), F, GSH oxidized (GSSG), G, GSH+GSSG, and $\mathbf{H}, \mathrm{GSH} / \mathrm{GSSG}$. These data were measured at 10 days after inoculation (dpi). I, Changes in expression of PbrAPX, J, PbrDHAR2, K, PbrMDHAR, and $\mathbf{L}, P b r G R$ under inoculation. Total RNA was isolated from leaf samples collected at 6 dpi. Expression in $\mathrm{H}_{2} \mathrm{O}$-treated leaves under control conditions was set to "1". Data are means of three replicates with standard error. Values not followed by the same letter indicate significant differences between treatments, according to one-way analysis of variance Tukey's multiple range tests $(P<0.05)$. 
Changes in activity of enzyme antioxidative system after calcium treatment under $B$. dothidea infection.

It is well-established that reactive oxygen species (ROS), also known as an oxidative burst, has been considered associated with plant resistance to pathogen infection (Lamb and Dixon 1997). To analyze the oxidative status after calcium treatment under $B$. dothidea infection, we examined the contents of $\mathrm{H}_{2} \mathrm{O}_{2}$ and $\mathrm{O}_{2}^{-}$, two major versatile and stable ROS. $\mathrm{H}_{2} \mathrm{O}_{2}$ and $\mathrm{O}_{2}^{-}$were induced in all leaves after inoculation. However, compared with $\mathrm{H}_{2} \mathrm{O}$ treatment, $\mathrm{Ca}^{2+}$ treatment significantly reduced ROS production. The $\mathrm{H}_{2} \mathrm{O}_{2}$ and $\mathrm{O}_{2}^{-}$contents of $\mathrm{Ca}^{2+}$ treated leaves were 19.63 and $21.90 \%$ lower than those of $\mathrm{H}_{2} \mathrm{O}$ treated leaves, respectively (Fig. 3).

We also analyzed antioxidant enzymes after inoculation. The superoxide dismutase (SOD), peroxidase (POD), catalase (CAT), and polyphenol oxidase (PPO) activities did not differ significantly between calcium-treated and control leaves
(Fig. 3). After inoculation, the SOD, POD, CAT, and PPO levels were elevated, but the activities of these enzymes were significantly higher in $\mathrm{Ca}^{2+}$-treated leaves than in $\mathrm{H}_{2} \mathrm{O}$ - treated leaves.

Changes in the ascorbic acid-glutathione (AsA-GSH) cycle after calcium treatment under $B$. dothidea infection.

The AsA-GSH cycle is a nonenzyme system involved in scavenging ROS (Conklin 2001; Gallie 2013; Sun et al. 2018b). Here, we detected the status of AsA, dehydroascorbate (DHA), $\mathrm{GSH}$, and oxidized GSH (GSSG) after $\mathrm{Ca}^{2+}$ treatment. $B$. dothidea infection significantly increased the AsA and DHA contents (Fig. 4A and B). The AsA level in $\mathrm{Ca}^{2+}$-treated leaves was 2.04 times that in $\mathrm{H}_{2} \mathrm{O}$-treated leaves (Fig. 4A). However, the DHA level did not differ between $\mathrm{Ca}^{2+}$ - and $\mathrm{H}_{2} \mathrm{O}$-treated leaves (Fig. 4B). The total ascorbate (AsA+DHA) level in $\mathrm{Ca}^{2+}$ treated leaves was significantly higher than that in $\mathrm{H}_{2} \mathrm{O}$-treated
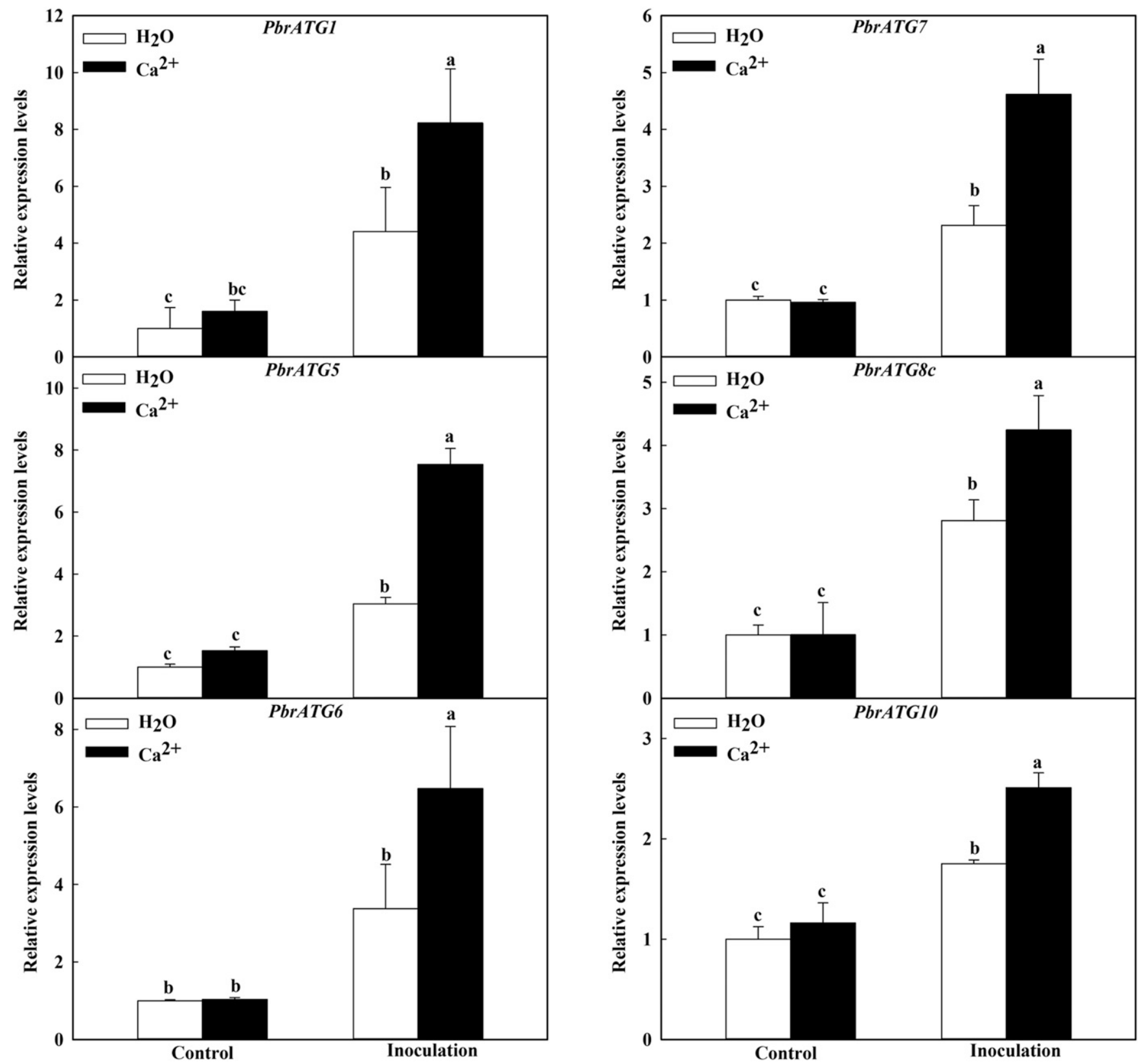

Fig. 5. Changes in expression of core ATGs of pear leaves under inoculation. Total RNA was isolated from leaf samples collected at 6 days after inoculation. Expression in $\mathrm{H}_{2} \mathrm{O}$-treated leaves under control conditions was set to "1". Data are means of three replicates with standard error. Values not followed by the same letter indicate significant differences between treatments, according to one-way analysis of variance Tukey's multiple range tests $(P<0.05)$. 
leaves under inoculation (Fig. 4C). This difference was more remarkable for the ratio of AsA to DHA (Fig. 4D). A consistent pattern was detected for the levels of GSH, GSSG, and the total GSH pool (Fig. 4E to G). For example, GSH content was obviously higher in $\mathrm{Ca}^{2+}$-treated leaves than in $\mathrm{H}_{2} \mathrm{O}$-treated leaves (Fig. 4E). The ratio of GSH to GSSG was much higher in $\mathrm{Ca}^{2+}$ treated leaves (Fig. 4G).

We also analyzed the expression levels of $A P X, D H A R 2$, $M D H A R$, and $G R$, four major genes involved in the AsA-GSH cycle. A similar change was observed in the levels and status of AsA and GSH. The expression levels of $A P X, D H A R 2$, $M D H A R$, and $G R$ were induced by pathogen infection at $6 \mathrm{dpi}$, especially in the $\mathrm{Ca}^{2+}$-treated leaves. For instance, the expression level of $A P X$ in $\mathrm{Ca}^{2+}$-treated leaves was 2.53 times that of $\mathrm{H}_{2} \mathrm{O}$-treated leaves under inoculation conditions (Fig. 4I). These results indicate that $\mathrm{Ca}^{2+}$ treatment improved the capacity to produce and to maintain higher levels of beneficial antioxidants under pathogen infection.

\section{Changes in the expression levels of core $A T G$ genes and autophagic activity after calcium treatment under $B$. dothidea infection.}

To explore the effect of $\mathrm{Ca}^{2+}$ treatment on autophagic activity under infection conditions, we first analyzed the expression levels of core $A T G$ genes. Under mock control conditions, the transcript levels of PbrATG1, PbrATG5, PbrATG6, PbrATG7, PbrATG $8 c$, and PbrATG10 did not differ between the $\mathrm{H}_{2} \mathrm{O}$ and $\mathrm{Ca}^{2+}$ treatment groups (Fig. 5). However, at $6 \mathrm{dpi}$, the expression levels of all genes were significantly higher in the $\mathrm{Ca}^{2+}$. treated leaves than in the $\mathrm{H}_{2} \mathrm{O}$-treated leaves.

To investigate the autophagy occurrence in response to $\mathrm{Ca}^{2+}$ treatment under pathogen infection, we used transmission electron microscopy (TEM) to detect the numbers of autophagosomes. As shown in Figure 6A, few autophagosomes were observed in all treated leaves under mock control conditions. When infected by B. dothidea, the number of autophagosomes and autophagic bodies that accumulated in $\mathrm{Ca}^{2+}$-treated leaf cells were higher than in $\mathrm{H}_{2} \mathrm{O}$-treated leaf cells (Fig. 6A and B). These results suggest that $\mathrm{Ca}^{2+}$ treatment increases autophagosome formation to enhance resistance to pathogen infection.

Calcium enhances resistance to $B$. dothidea in pear plants in an autophagy-dependent manner.

To deeply explore the mechanism by which calcium affects the resistance of pear plants to $B$. dothidea, we performed the virus-induced gene silencing (VIGS) of a key gene in autophagy,
PbrATG5, in P. betulaefolia. As shown in Figure 7A, the expression level of PbrATG5 was significantly lower in TRV2PbrATG5 pear plants than in TRV2 plants. Silencing of PbrATG5 significantly increased the disease diameter under $\mathrm{H}_{2} \mathrm{O}$ treatment (Fig. 7B). However, the calcium treatment produced only a slight recovery of the symptoms of inoculation in TRV2PbrATG5 pear plants (reduced by 14.2\%) compared with TRV2 control plants (reduced by $58.8 \%$ ) (Fig. 7C). These results indicated that calcium enhance the resistance of pear plants, at least in part, through autophagy.

\section{Changes in SA accumulation and expression levels of SA-related genes after calcium treatment under B. dothidea infection.}

Many articles have reported that SA plays a role in the plant immunity response (Dong 2004; Fu et al. 2012; Hofius et al. 2017; Sun et al. 2018b; Zhao et al. 2019). To explore SA synthesis in response to $\mathrm{Ca}^{2+}$ treatment, we detected SA concentrations. In Figure $8 \mathrm{~A}$, the SA level was induced by $\mathrm{Ca}^{2+}$ under pathogen infection. For the inoculation, the SA content was 1.83 times higher in the $\mathrm{Ca}^{2+}$-treated leaves than in the $\mathrm{H}_{2} \mathrm{O}$-treated leaves. Two SA synthesis genes, ICS1 and EDSI, were more highly expressed in $\mathrm{Ca}^{2+}$-treated leaves than in $\mathrm{H}_{2} \mathrm{O}$ treated leaves, whereas the transcription of these genes was not different under the mock control condition. Furthermore, the expression levels of three SA-related genes, NPR1, PR1, and $P R 5$, were higher in the $\mathrm{Ca}^{2+}$-treated leaves than in the $\mathrm{H}_{2} \mathrm{O}$ treated leaves. In addition, expression of genes involved in the jasmonic acid (JA) and ethylene pathway were also examined. As shown in Supplementary Figure S1, the expression of the JA-related genes $P b r P R 3$ and PbrPR4 was significantly reduced in $\mathrm{Ca}^{2+}$-treated leaves under inoculation. The expression levels of two ethylene synthesis genes that have been studied previously, PbrACS1B (Shi et al. 2013) and PbrACO54 (Hao et al. 2017), were also examined. As shown in Supplementary Figure S1, the expression of PbrACS1B and PbrACO54 was induced by Botryosphaeria dothidea. However, the expression levels of PbrACS1B and PbrACO54 were lower after calcium treatment than after $\mathrm{H}_{2} \mathrm{O}$ treatment under inoculation. These results indicated that calcium treatment enhanced SA-related gene expression.

\section{DISCUSSION}

Calcium has been reported to participate in plant metabolism (Kou et al. 2014, 2015; Yuan et al. 2017). Previous studies
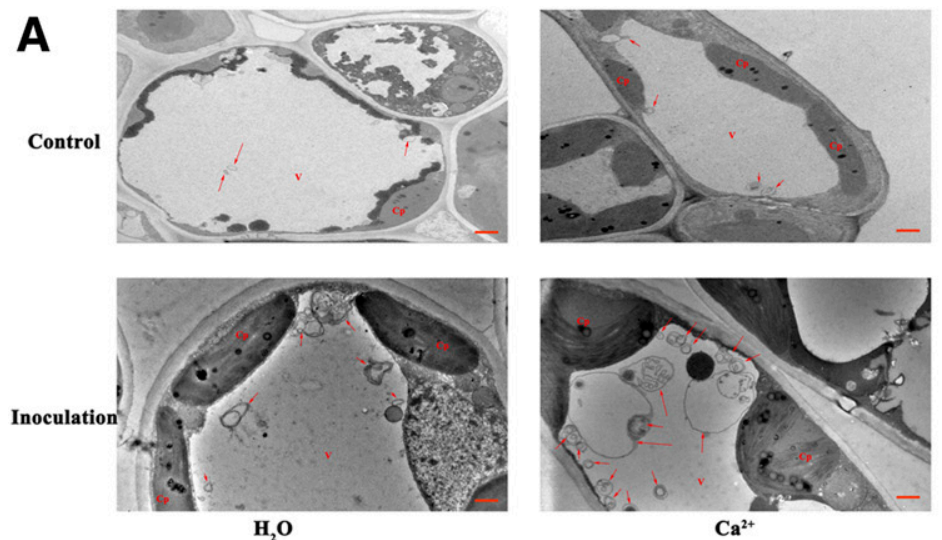

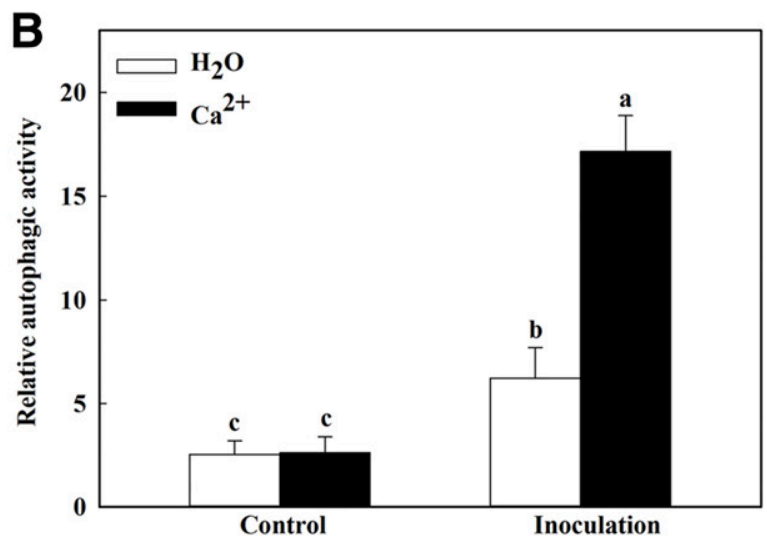

Fig. 6. Accumulation of autophagosomes under inoculation. A, Representative transmission electron microscopy images of autophagic structures in mesophyll cells from $\mathrm{H}_{2} \mathrm{O}$ - and $\mathrm{Ca}^{2+}$-treated leaves. Bars $=1 \mu \mathrm{m}$. B, Relative autophagic activity normalized to the activity of $\mathrm{H}_{2} \mathrm{O}-$ and $\mathrm{Ca}^{2+}$-treated leaves shown in $\mathrm{A}$. More than 10 cells were used to quantify structures. Data are means of three replicates with standard error. Values not followed by the same letter indicate significant differences between treatments, according to one-way analysis of variance Tukey's multiple range tests $(P<0.05)$. 

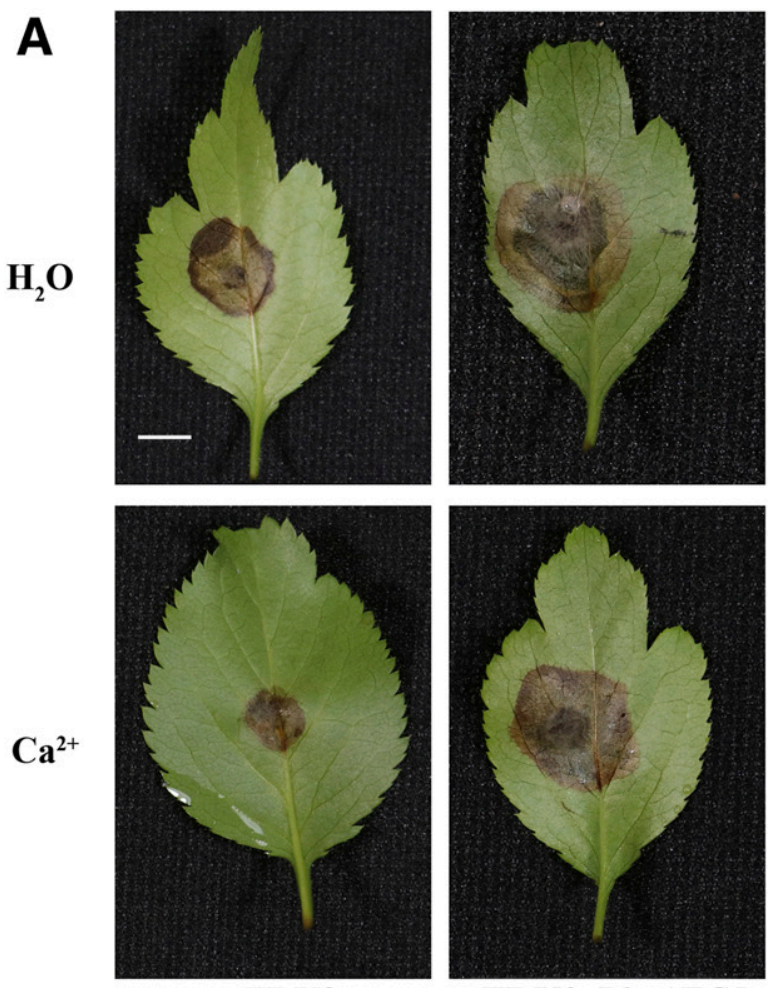

TRV2

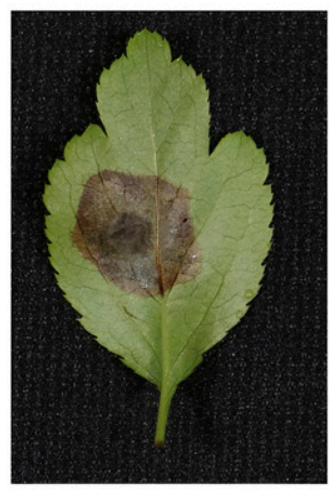

TRV2-PbrATG5
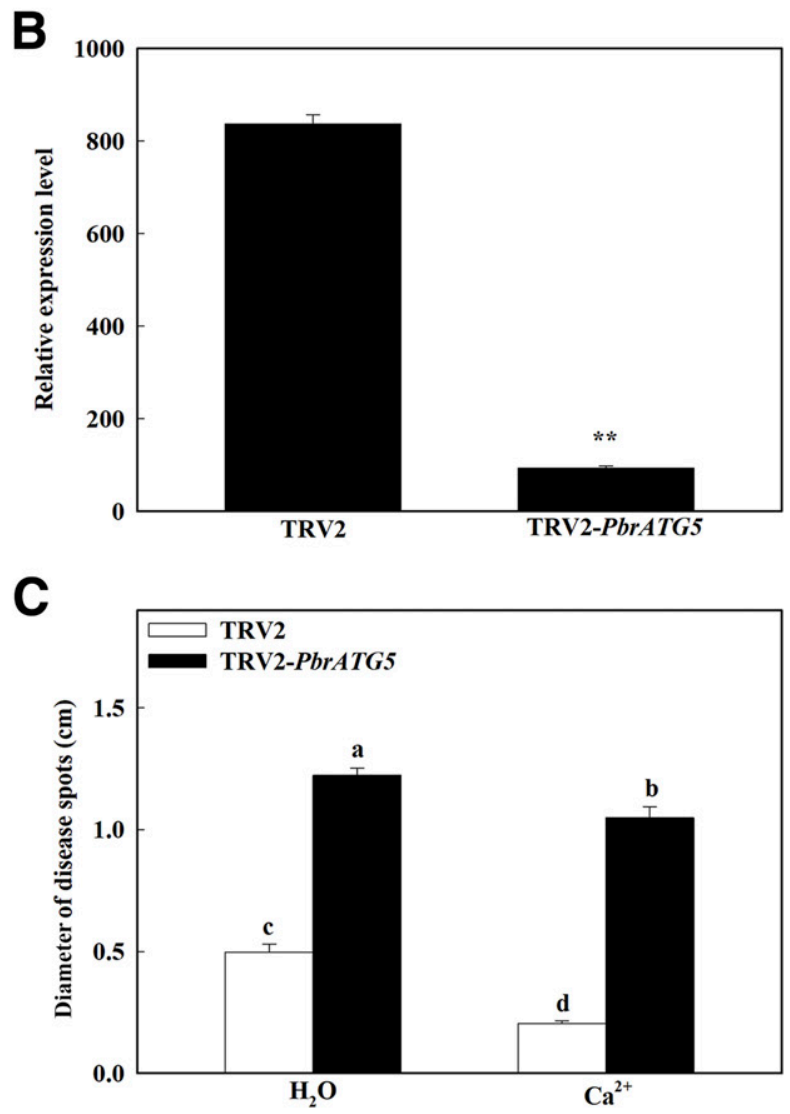

Fig. 7. Silencing of PbrATG5 decreased the resistance to Botryosphaeria dothidea and led to only a slight recovery by calcium treatment. A, Phenotype of TRV2 and TRV2-PbrATG5 leaves infected by $B$. dothidea under calcium and $\mathrm{H}_{2} \mathrm{O}$ treatment at 6 days after inoculation. B, The expression level of PbrATG5 in Pyrus betulaefolia. C, Diameter of disease spots of PbrATG5silenced plants. Data are means of three replicates with standard error. Asterisks denote statistically significant differences between TRV2 and TRV2-PbrATG5 plants (asterisks [**] mean $P<0.01$, analysis of variance). found that exogenous calcium treatment could promote plant senescence, yield, fruit browning, and abiotic tolerance (Kou et al. 2014, 2015; Yin et al. 2015). However, little is known about the effect and mechanism of exogenous calcium application in plant immunity. Here, we sprayed $1 \% \mathrm{CaCl}_{2}$ on pear leaves to detect resistance to $B$. dothidea infection. We found that exogenous $\mathrm{Ca}^{2+}$ treatment significantly enhanced resistance to $B$. dothidea. The $\mathrm{Ca}^{2+}$ treatment increased the total calcium concentrations in the pear leaves. The $\mathrm{Ca}^{2+}$-treated leaves accumulated fewer ROS and showed enhanced activities of ROS-scavenging enzymes and capacity for AsA-GSH recycling under inoculation. Most importantly, under inoculation conditions, the activity of autophagy and the level of $\mathrm{SA}$ was significantly higher in the $\mathrm{Ca}^{2+}$-treated leaves than in the $\mathrm{H}_{2} \mathrm{O}$-treated leaves. These results suggested that exogenous $\mathrm{Ca}^{2+}$ treatment enhanced resistance to infection by B. dothidea.

Previous studies found that appropriate $\mathrm{Ca}^{2+}$ concentrations could benefit plant development and adaptation to stress, but excessive calcium application may impair normal metabolism in plant (Kou et al. 2014). Our results indicate that the effect of exogenous calcium on resistance to $B$. dothidea is dosedependent. The $1 \% \mathrm{CaCl}_{2}$ treatment resulted in the best resistance. However, high doses of calcium application (2 to 4\% $\mathrm{CaCl}_{2}$ ) showed a decreased effect on resistance. As the second messenger, calcium is involved in multiple cellular processes via transmitting signals received at the cell surface to the interior by changes in cytosol concentrations, which are decoded by a series of $\mathrm{Ca}^{2+}$ sensors (Kudla et al. 2010; Ranty et al. 2016; Yang and Poovaiah 2003). Under normal conditions, intracellular calcium concentration can be well controlled by calcium influx and efflux mechanisms in the cell membrane; however, the excessive application of calcium affects the balance of calcium influx and efflux, resulting in disordered intracellular calcium (Kudla et al. 2010; Steinhorst and Kudla 2014). These uncontrolled changes in calcium concentration ultimately lead to cell damage. Further research is needed to explore the molecular mechanisms underlying the role of excessive calcium in resistance to pathogen infection.

The ROS stimulated by pathogens are highly reactive and, therefore, toxic and participate in several important processes related to defense and infection (Shetty et al. 2008). $\mathrm{H}_{2} \mathrm{O}_{2}$ and $\mathrm{O}_{2}^{-}$are two major and stable ROS. In our study, the content of $\mathrm{H}_{2} \mathrm{O}_{2}$ and $\mathrm{O}_{2}^{-}$was significantly lower in the $\mathrm{Ca}^{2+}$-treated leaves than in the $\mathrm{H}_{2} \mathrm{O}$-treated leaves under inoculation conditions. This result was consistent with a previous study that reported lower ROS accumulation in more resistant apple plants under pathogen infection (Sun et al. 2018b; Zhao et al. 2019). Plants utilize both enzymatic and nonenzymatic mechanisms to scavenge ROS (Cheng et al. 2016; Sun et al. 2018b; Xing et al. 2019). Here, the activities of SOD and POD were significantly higher in $\mathrm{Ca}^{2+}$-treated leaves under inoculation. Similarly, as the nonenzymatic system for scavenging ROS, the AsA-GSH cycle was maintained at a reduced status by $\mathrm{Ca}^{2+}$ treatment under inoculation. Moreover, four genes located in different cellular compartments that work in conjunction with the AsAGSH cycle, namely, APX, DHAR, MDHAR, and GR, were expressed at higher levels in the $\mathrm{Ca}^{2+}$-treated leaves than in the $\mathrm{H}_{2} \mathrm{O}$-treated leaves under $B$. dothidea infection. Previous studies indicated that enhanced autophagy activity led to the modification of the antioxidant system (Sun et al. 2018a and b). Thus, the higher antioxidative status in the $\mathrm{Ca}^{2+}$-treated leaves may result from the higher activity of autophagy.

Numerous studies in mammals have reported that calcium stimulates autophagy by calcium sensors (East and Campanella 2013; Kondratskyi et al. 2018; La Rovere et al. 2016). In Arabidopsis, CML24 affects autophagy progression by interacting 
with ATG4 (Tsai et al. 2013). Autophagy deficiency in Arabidopsis mutants showed spreading necrotic lesions and enhanced fungal growth upon infection with necrotrophic pathogen (Lai et al. 2011; Lenz et al. 2011). These results indicated that autophagy enhances plant resistance to necrotrophic pathogens. In our study, the $\mathrm{Ca}^{2+}$-treated pear leaves accumulated more autophagosomes than did $\mathrm{H}_{2} \mathrm{O}$-treated leaves under inoculation. Moreover, the expression levels of core ATG genes was significantly increased in $\mathrm{Ca}^{2+}$-treated leaves compared with $\mathrm{H}_{2} \mathrm{O}$ treated leaves under $B$. dothidea infection. The resistance of PbrATG5-silenced pear leaves was decreased and calcium treatment only slightly restricted disease spots under inoculation. These results suggested that the increased autophagy activity was attributed to the enhanced resistance to $B$. dothidea. Our discoveries provide evidence that autophagy could be activated by $\mathrm{Ca}^{2+}$.

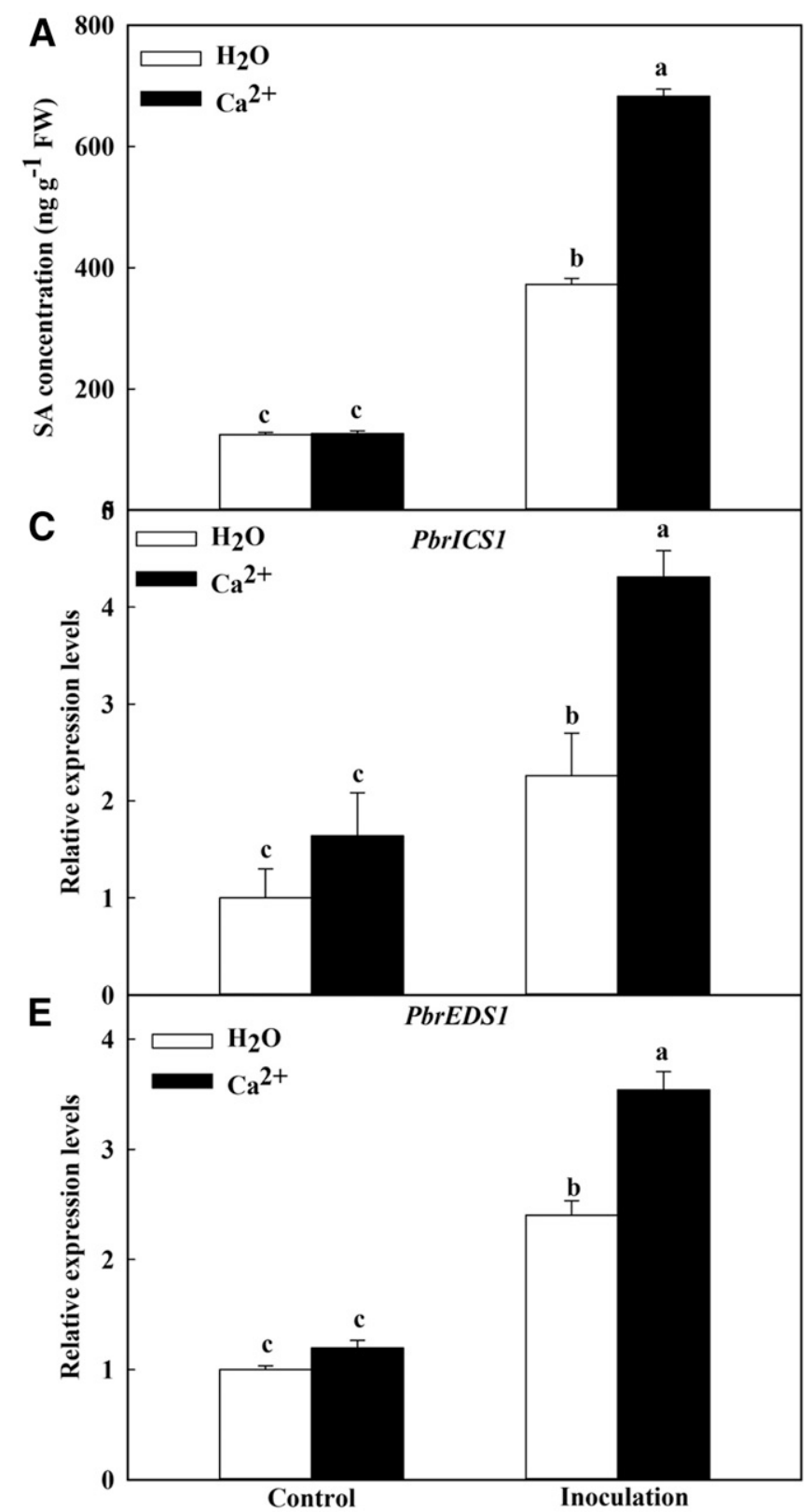

Previous studies indicated that a mechanism connects $\mathrm{Ca}^{2+}$ signals to the SA-mediated immune response (Coca and San Segundo 2010; Du et al. 2009; Wang et al. 2009). SA is involved in both local defense responses at the infection site and the activation of systemic resistance (Robert-Seilaniantz et al. 2011). CBP60g contributes to microbe-associated molecular pattern-triggered SA accumulation in Arabidopsis (Wang et al. 2009). AtCPK1 enhances the resistance of Arabidopsis to pathogens by regulating the accumulation of SA and the expression of SA-related genes (Coca and San Segundo 2010). These results indicated that SA content is an important factor in the regulation of plant resistance to pathogens. Here, the $\mathrm{Ca}^{2+}$ treated leaves accumulated higher levels of SA than did the $\mathrm{H}_{2} \mathrm{O}$-treated leaves. It was demonstrated that exogenous $\mathrm{Ca}^{2+}$ increased SA synthesis. Two SA synthesis genes, ICS1 and $E D S 1$, were more strongly induced in the $\mathrm{Ca}^{2+}$-treated leaves

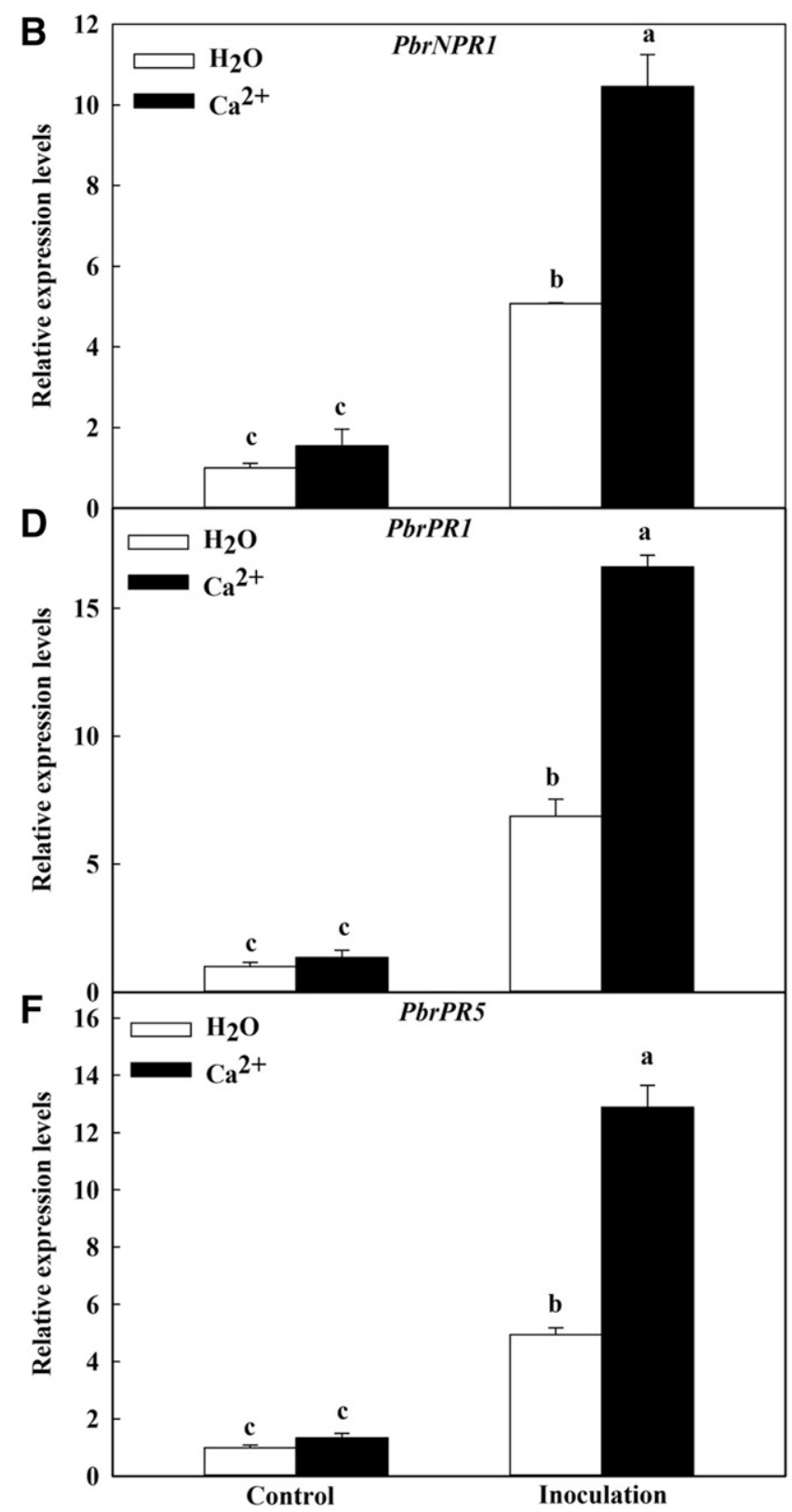

Fig. 8. Changes in salicylic acid (SA) synthesis and expression of SA-related genes. A, SA content was measured at 10 days after inoculation (dpi). B through $\mathbf{F}$, Expression of PbrICS1, PbrEDS1, PbrNPR1, PbrPR1, and PbrPR 5 was analyzed at 6 dpi. Expression in $\mathrm{H}_{2} \mathrm{O}$-treated leaves under control conditions was set to "1". Data are means of three replicates with standard error. Values not followed by the same letter indicate significant differences between treatments, according to one-way analysis of variance Tukey's multiple range tests $(P<0.05)$. 
after inoculation. SA signaling was transduced by the NPRI gene and elevated $P R$ gene expression to enhance disease resistance (Ding et al. 2018; Hussain et al. 2018). We noted here that the expression levels of PbrNPR1, PbrPR1, and PbrPR5 were elevated by $\mathrm{Ca}^{2+}$ treatment compared with $\mathrm{H}_{2} \mathrm{O}$ treatment. These results demonstrated that $\mathrm{Ca}^{2+}$ regulated the SA pathway and contributed to pathogen resistance.

In conclusion, exogenous calcium treatment enhanced resistance to $B$. dothidea by increasing autophagic activity and $\mathrm{SA}$ level in pear. The $\mathrm{Ca}^{2+}$-treated pear leaves accumulated lower levels of ROS and showed higher SOD and POD activity. The AsA-GSH cycle was maintained at a more-reductive redox state by increasing the total calcium content. This might result from by enhanced autophagic activity, as supported by the elevated expression of core PbrATG genes and the increase in autophagosome formation. The SA pathway was activated more by $\mathrm{Ca}^{2+}$ treatment than by $\mathrm{H}_{2} \mathrm{O}$ treatment under inoculation. These results provide further insight into the function of calcium in pear disease resistance. We can use the strategy of exogenous calcium spraying on the leaf, which could induce autophagy and SA to alleviate pathogen infections according to our results.

\section{MATERIALS AND METHODS}

\section{Plant materials and treatments.}

Healthy mature leaves of Dangshan Su pear (Pyrus bretschneideri Rehd.), obtained from the 'Hu Shu' pear orchard of Nanjing Agricultural University, were detached with their complete petioles and were immediately taken to the laboratory. After the leaves were prepared and surface-sterilized with $0.1 \%$ sodium hypochlorite for $10 \mathrm{~min}$, the preprocessed leaves were washed with sterile water three times, and the petioles were cut short underwater, to prevent gas bolting and were wrapped with wet absorbent gauze. The leaves were then sprayed with 0.5 to $4 \% \mathrm{CaCl}_{2}$ and double-distilled $\mathrm{H}_{2} \mathrm{O}$ solutions containing $0.05 \%$ Tween-20. After $12 \mathrm{~h}$, the leaves were wounded at four locations, using a sterile needle. The wounded samples were inoculated with mycelium agar ( $5 \mathrm{~mm}$ diameter) obtained from the edge of an activated colony of $B$. dothidea on potato dextrose agar (PDA) or control PDA agar. They were then incubated in the dark in a chamber held at a constant $25^{\circ} \mathrm{C}$ and $80 \%$ relative humidity. A total of 180 leaves in four plastic boxes were inoculated or not inoculated under $\mathrm{CaCl}_{2}$ and $\mathrm{H}_{2} \mathrm{O}$ treatment, with four inoculation sites per leaf. Five entire leaves were sampled per repeat at 0,6 , and $10 \mathrm{dpi}$. Leaves were sampled three times as three repeats with a total of 15 leaves at each sampling time.

\section{Total calcium content detection.}

The total calcium content was measured as described previously (Codling et al. 2007; Kou et al. 2014). Briefly, at 6 dpi, the entire leaves were rinsed three times with double distilled water to remove any surface calcium before drying in a $70^{\circ} \mathrm{C}$ oven for $48 \mathrm{~h}$. The over-dried leaf tissues $(0.5 \mathrm{~g})$ were ashed at $550^{\circ} \mathrm{C}$ for $16 \mathrm{~h}$, followed by the addition of $5 \mathrm{ml}$ of concentrated nitric acid; samples were then dried on a hot plate. After drying, the digest volumes were brought to $25 \mathrm{ml}$ with $0.1 \mathrm{M}$ $\mathrm{HCl}$. The calcium concentration in the tissue was determined using the Optima 4300 DV inductively coupled plasma optical emission spectrometer (PerkinElmer), with strontium as an internal standard.

Detection of $\mathrm{H}_{2} \mathrm{O}_{2}, \mathrm{O}_{2}^{-}$, and antioxidant metabolites.

The $\mathrm{H}_{2} \mathrm{O}_{2}, \mathrm{O}_{2}^{-}$, CAT, PPO, POD, SOD, AsA, DHA, GSH, and GSSG detection assays were performed according to manufacturer instructions (Comin).

\section{RNA extraction and real-time PCR.}

Total RNA was extracted according to a CTAB method. Firststrand cDNA synthesis and real-time PCR were performed as previously described (Xing et al. 2019). Tubulin was used as internal control. Primer sequences for real-time PCR are listed in Supplementary Table S1. Each experiment was repeated three times biologically, based on three separate RNA extracts from three repeats.

\section{Autophagosome detection by TEM.}

At 6 dpi, small pieces of mesophyll located at the border of the disease spot were cut from the leaves and, then, were fixed with $2.5 \%$ glutaraldehyde in $0.2 \mathrm{M}$ phosphate buffered saline $(\mathrm{pH} 7.4)$ before being placed in the dark for $12 \mathrm{~h}$ at $4^{\circ} \mathrm{C}$. Our TEM analysis was performed as previously described (Sun et al. 2018a).

\section{Vector construction and plant transformation.}

Tobacco rattle virus-based vector (pTRV1/2) constructs were used for VIGS (Xing et al. 2019). To construct of pTRVPbrATG5, a fragment of the PbrATG5 open reading frame (306 bp, 420 to 725 bp) was amplified by PCR, which was then introduced into the pTRV2 vector. The primer was shown in Supplementary Table S1. VIGS of PbrATG5 was performed as previously described (Xing et al. 2019).

\section{Detection of SA content.}

SA was extracted and quantified as described previously (Fu et al. 2012; Sun et al. 2018b). Leaf samples (0.1 g) were homogenized in liquid nitrogen and were placed in $1 \mathrm{ml}$ of $90 \%$ methanol. 3-Hydroxybenzoic acid (Sigma) was added as internal standard. Extracts were analyzed though a fluorescence detector (excitation at $305 \mathrm{~nm}$ and emission at $405 \mathrm{~nm}$ ) on a Zorbax SB-C18 column (Agilent Technologies).

\section{Statistical analysis.}

Experimental data are presented as the means \pm standard deviations of three independent replicates. Data were analyzed via analysis of variance, and mean values were compared by Tukey's multiple range test $(P<0.05)$. All the statistical analyses were performed using SPSS18 statistical software package (IBM SPSS Statistics).

\section{ACKNOWLEDGMENTS}

The authors are grateful to F. Liu for providing Botryosphaeria dothidea

\section{LITERATURE CITED}

Aldon, D., Mbengue, M., Mazars, C., and Galaud, J. P. 2018. Calcium signalling in plant biotic interactions. Int. J. Mol. Sci. 19:665.

Bai, S., Dong, C., Li, B., and Dai, H. 2013. A PR-4 gene identified from Malus domestica is involved in the defense responses against Botryosphaeria dothidea. Plant Physiol. Biochem. 62:23-32.

Bender, K. W., and Snedden, W. A. 2013. Calmodulin-related proteins step out from the shadow of their namesake. Plant Physiol. 163:486-495.

Bundó, M., and Coca, M. 2016. Enhancing blast disease resistance by overexpression of the calcium-dependent protein kinase $\mathrm{OSCPK} 4$ in rice. Plant Biotechnol. J. 14:1357-1367.

Cheng, F., Yin, L. L., Zhou, J., Xia, X. J., Shi, K., Yu, J. Q., Zhou, Y. H., and Foyer, C. H. 2016. Interactions between 2-Cys peroxiredoxins and ascorbate in autophagosome formation during the heat stress response in Solanum lycopersicum. J. Exp. Bot. 67:1919-1933.

Cheng, S.-H., Willmann, M. R., Chen, H.-C., and Sheen, J. 2002. Calcium signaling through protein kinases. The Arabidopsis calcium-dependent protein kinase gene family. Plant Physiol. 129:469-485.

Chung, T., Suttangkakul, A., and Vierstra, R. D. 2009. The ATG autophagic conjugation system in maize: ATG transcripts and abundance of the ATG8-lipid adduct are regulated by development and nutrient availability. Plant Physiol. 149:220-234. 
Coca, M., and San Segundo, B. 2010. AtCPK1 calcium-dependent protein kinase mediates pathogen resistance in Arabidopsis. Plant J. 63:526-540.

Codling, E., Mulchi, C., and Chaney, R. 2007. Grain yield and mineral element composition of maize grown on high phosphorus soils amended with water treatment residual. J. Plant Nutr. 30:225-240.

Conklin, P. L. 2001. Recent advances in the role and biosynthesis of ascorbic acid in plants. Plant Cell Environ. 24:383-394.

Dai, X., Li, Z., and Gong, M. 2012. Effect of gibberellin, calcium, and betaine on seed germination and resistance of Jatropha curcas 1. seedlings to low temperature and drought stress. Plant Sci. J. 30:204-212.

Day, I. S., Reddy, V. S., Ali, G. S., and Reddy, A. 2002. Analysis of EF-handcontaining proteins in Arabidopsis. Genome Biol. 3:research0056.1.

Ding, Y., Sun, T., Ao, K., Peng, Y., Zhang, Y., Li, X., and Zhang, Y. 2018. Opposite roles of salicylic acid receptors NPR1 and NPR3/NPR4 in transcriptional regulation of plant immunity. Cell 173:1454-1467. e1415.

Dong, X. 2004. NPR1, all things considered. Curr. Opin. Plant Biol. 7: $547-552$.

Du, L., Ali, G. S., Simons, K. A., Hou, J., Yang, T., Reddy, A. S., and Poovaiah, B. W. 2009. $\mathrm{Ca}^{2+} /$ calmodulin regulates salicylic-acidmediated plant immunity. Nature 457:1154-1158.

East, D. A., and Campanella, M. 2013. $\mathrm{Ca}^{2+}$ in quality control: An unresolved riddle critical to autophagy and mitophagy. Autophagy 9: 1710-1719.

Farré, J.-C., and Subramani, S. 2016. Mechanistic insights into selective autophagy pathways: Lessons from yeast. Nat. Rev. Mol. Cell Biol. 17: 537-552.

Filippi-Chiela, E. C., Viegas, M. S., Thomé, M. P., Buffon, A., Wink, M. R., and Lenz, G. 2016. Modulation of autophagy by calcium signalosome in human disease. Mol. Pharmacol. 90:371-384.

Fu, Z. Q., Yan, S., Saleh, A., Wang, W., Ruble, J., Oka, N., Mohan, R., Spoel, S. H., Tada, Y., Zheng, N., and Dong, X. 2012. NPR3 and NPR4 are receptors for the immune signal salicylic acid in plants. Nature 486 : 228-232.

Gallie, D. R. 2013. The role of L-ascorbic acid recycling in responding to environmental stress and in promoting plant growth. J. Exp. Bot. 64: 433-443.

Han, S., Wang, Y., Zheng, X., Jia, Q., Zhao, J., Bai, F., Hong, Y., and Liu, Y. 2015. Cytoplastic glyceraldehyde-3-phosphate dehydrogenases interact with ATG3 to negatively regulate autophagy and immunity in Nicotiana benthamiana. Plant Cell 27:1316-1331.

Hao, P. P., Wang, G.-M., Cheng, H.-Y., Ke, Y.-Q., Qi, K.-J., Gu, C., and Zhang, S.-L. 2017. Transcriptome analysis unravels an ethylene response factor involved in regulating fruit ripening in pear. Physiol. Plant. 163: 124-135.

He, C., and Klionsky, D. J. 2009. Regulation mechanisms and signaling pathways of autophagy. Annu. Rev. Genet. 43:67-93.

He, X., Huo, Y., Liu, X., Zhou, Q., Feng, S., Shen, X., Li, B., Wu, S., and Chen, X. 2018. Activation of disease resistance against Botryosphaeria dothidea by downregulating the expression of MdSYP121 in apple. Hortic. Res. 5:24.

Hofius, D., Li, L., Hafrén, A., and Coll, N. S. 2017. Autophagy as an emerging arena for plant-pathogen interactions. Curr. Opin. Plant Biol. 38:117-123

Høyer-Hansen, M., Bastholm, L., Szyniarowski, P., Campanella, M., Szabadkai, G., Farkas, T., Bianchi, K., Fehrenbacher, N., Elling, F., Rizzuto, R., Mathiasen, I. S., and Jäättelä, M. 2007. Control of macroautophagy by calcium, calmodulin-dependent kinase kinase- $\beta$, and Bcl-2. Mol. Cell 25:193-205.

Hussain, R. M. F., Sheikh, A. H., Haider, I., Quareshy, M., and Linthorst, H. J. M. 2018. Arabidopsis WRKY50 and TGA transcription factors synergistically activate expression of PR1. Front. Plant Sci. 9:930.

Khan, M. N., Siddiqui, M. H., Mohammad, F., Naeem, M., and Khan, M. M. A. 2010. Calcium chloride and gibberellic acid protect linseed (Linum usitatissimum L.) from $\mathrm{NaCl}$ stress by inducing antioxidative defence system and osmoprotectant accumulation. Acta Physiol. Plant. 32:121-132.

Kim, K. W., Park, E. W., Kim, Y. H., Ahn, K.-K., Kim, P. G., and Kim, K. S. 2001. Latency-and defense-related ultrastructural characteristics of apple fruit tissues infected with Botryosphaeria dothidea. Phytopathology 91:165-172.

Kondratskyi, A., Kondratska, K., Skryma, R., Klionsky, D. J., and Prevarskaya, N. 2018. Ion channels in the regulation of autophagy. Autophagy 14:3-21.

Kou, L., Yang, T., Luo, Y., Liu, X., Huang, L., and Codling, E. 2014. Preharvest calcium application increases biomass and delays senescence of broccoli microgreens. Postharvest Biol. Technol. 87:70-78.

Kou, X., Wu, M., Li, L., Wang, S., Xue, Z., Liu, B., and Fei, Y. 2015. Effects of $\mathrm{CaCl}_{2}$ dipping and pullulan coating on the development of brown spot on 'Huangguan' pears during cold storage. Postharvest Biol. Technol. 99:63-72.

Kudla, J., Batistič, O., and Hashimoto, K. 2010. Calcium signals: The lead currency of plant information processing. Plant Cell 22:541-563.

La Rovere, R. M., Roest, G., Bultynck, G., and Parys, J. B. 2016 Intracellular $\mathrm{Ca}^{2+}$ signaling and $\mathrm{Ca}^{2+}$ microdomains in the control of cell survival, apoptosis and autophagy. Cell Calcium 60:74-87.

Lai, Z., Wang, F., Zheng, Z., Fan, B., and Chen, Z. 2011. A critical role of autophagy in plant resistance to necrotrophic fungal pathogens. Plant $\mathrm{J}$. 66:953-968.

Lamb, C., and Dixon, R. A. 1997. The oxidative burst in plant disease resistance. Annu. Rev. Plant Physiol. Plant Mol. Biol. 48:251-275.

Lenz, H. D., Haller, E., Melzer, E., Gust, A. A., and Nürnberger, T. 2011. Autophagy controls plant basal immunity in a pathogenic lifestyledependent manner. Autophagy 7:773-774.

Li, Y., Kabbage, M., Liu, W., and Dickman, M. B. 2016. Aspartyl proteasemediated cleavage of BAG6 is necessary for autophagy and fungal resistance in plants. Plant Cell 28:233-247.

Liu, B., Luo, C., Li, X., Gray, L., Zhang, F., Liu, M., Ju, J., and Lei, B. 2014 Research on the threshold of aluminum toxicity and the alleviation effects of exogenous calcium, phosphorus, and nitrogen on the growth of Chinese fir seedlings under aluminum stress. Commun. Soil Sci. Plant Anal. 45:126-139.

Liu, N., Hake, K., Wang, W., Zhao, T., Romeis, T., and Tang, D. 2017. CALCIUM-DEPENDENT PROTEIN KINASE5 associates with the truncated NLR protein TIR-NBS2 to contribute to exo70B1-mediated immunity. Plant Cell 29:746-759.

Liu, Y., and Bassham, D. C. 2012. Autophagy: Pathways for self-eating in plant cells. Annu. Rev. Plant Biol. 63:215-237.

Lu, Y., Truman, W., Liu, X., Bethke, G., Zhou, M., Myers, C. L., Katagiri, F., and Glazebrook, J. 2018. Different modes of negative regulation of plant immunity by calmodulin-related genes. Plant Physiol. 176:3046-3061.

Luan, S. 2009. The CBL-CIPK network in plant calcium signaling. Trends Plant Sci. 14:37-42.

Qi, H., Xia, F. N., Xie, L. J., Yu, L. J., Chen, Q. F., Zhuang, X. H., Wang, Q., Li, F., Jiang, L., Xie, Q., and Xiao, S. 2017. TRAF family proteins regulate autophagy dynamics by modulating AUTOPHAGY PROTEIN6 stability in Arabidopsis. Plant Cell 29:890-911.

Ranty, B., Aldon, D., Cotelle, V., Galaud, J. P., Thuleau, P., and Mazars, C. 2016. Calcium sensors as key hubs in plant responses to biotic and abiotic stresses. Front. Plant Sci. 7:327.

Rao, S. S., El-Habbak, M. H., Havens, W. M., Singh, A., Zheng, D., Vaughn, L., Haudenshield, J. S., Hartman, G. L., Korban, S. S., and Ghabrial, S. A. 2014. Overexpression of GmCaM4 in soybean enhances resistance to pathogens and tolerance to salt stress. Mol. Plant Pathol. 15: 145-160.

Robert-Seilaniantz, A., Grant, M., and Jones, J. D. 2011. Hormone crosstalk in plant disease and defense: More than just jasmonate-salicylate antagonism. Annu. Rev. Phytopathol. 49:317-343.

Shetty, N. P., Jørgensen, H. J. L., Jensen, J. D., Collinge, D. B., and Shetty, H. S. 2008. Roles of reactive oxygen species in interactions between plants and pathogens. Eur. J. Plant Pathol. 121:267-280.

Shi, H., Wang, Y., Qi, A., Zhang, Y., Xu, J., Wang, A., and Zhang, Y. 2013. $P p A C S 1 b$, a pear gene encoding ACC synthase, is regulated during fruit late development and involved in response to salicylic acid. Sci. Hortic. (Amsterdam) 164:602-609.

Shibutani, S. T., and Yoshimori, T. 2014. A current perspective of autophagosome biogenesis. Cell Res. 24:58-68.

Steinhorst, L., and Kudla, J. 2014. Signaling in cells and organisms-Calcium holds the line. Curr. Opin. Plant Biol. 22:14-21.

Sun, X., Huo, L., Jia, X., Che, R., Gong, X., Wang, P., and Ma, F. 2018b. Overexpression of MdATG18a in apple improves resistance to Diplocarpon mali infection by enhancing antioxidant activity and salicylic acid levels. Hortic. Res. 5:57.

Sun, X., Wang, P., Jia, X., Huo, L., Che, R., and Ma, F. 2018a. Improvement of drought tolerance by overexpressing MdATG18a is mediated by modified antioxidant system and activated autophagy in transgenic apple. Plant Biotechnol. J. 16:545-557.

Tsai, Y.-C., Koo, Y., Delk, N. A., Gehl, B., and Braam, J. 2013. Calmodulinrelated CML24 interacts with ATG4b and affects autophagy progression in Arabidopsis. Plant J. 73:325-335.

Wang, L., Tsuda, K., Sato, M., Cohen, J. D., Katagiri, F., and Glazebrook, J. 2009. Arabidopsis CaM binding protein CBP60g contributes to MAMPinduced SA accumulation and is involved in disease resistance against Pseudomonas syringae. PLoS Pathog. 5:e1000301.

Xing, C., Liu, Y., Zhao, L., Zhang, S., and Huang, X. 2019. A novel MYB transcription factor regulates ascorbic acid synthesis and affects cold tolerance. Plant Cell Environ. 42:832-845. 
Yang, F., Kimberlin, A. N., Elowsky, C. G., Liu, Y., Gonzalez-Solis, A., Cahoon, E. B., and Alfano, J. R. 2019. A plant immune receptor degraded by selective autophagy. Mol. Plant 12:113-123.

Yang, T., and Poovaiah, B. W. 2003. Calcium/calmodulin-mediated signal network in plants. Trends Plant Sci. 8:505-512.

Yang, X., and Bassham, D. C. 2015. New insight into the mechanism and function of autophagy in plant cells. Pages 1-40 in: International Review of Cell and Molecular Biology, Elsevier, New York.

Yin, Y., Yang, R., Han, Y., and Gu, Z. 2015. Comparative proteomic and physiological analyses reveal the protective effect of exogenous calcium on the germinating soybean response to salt stress. J. Proteomics 113:110-126.
Yuan, P., Jauregui, E., Du, L., Tanaka, K., and Poovaiah, B. W. 2017. Calcium signatures and signaling events orchestrate plant-microbe interactions. Curr. Opin. Plant Biol. 38:173-183.

Zeng, H., Xu, L., Singh, A., Wang, H., Du, L., and Poovaiah, B. W. 2015. Involvement of calmodulin and calmodulin-like proteins in plant responses to abiotic stresses. Front. Plant Sci. 6:600.

Zhao, X. Y., Qi, C. H., Jiang, H., Zhong, M. S., You, C. X., Li, Y. Y., and Hao, Y. J. 2019. MdWRKY15 improves resistance of apple to Botryosphaeria dothidea via the salicylic acid-mediated pathway by directly binding the MdICS1 promoter. J. Integr. Plant Biol. 62: 527-543. 